\title{
SEGURANÇA ALIMENTAR E BIOCOMBUSTÍVEIS NO BRASIL
}

Valdecir José ZONIN ${ }^{1}$

Cesar Augustus WINCK ${ }^{2}$

João Armando Dessimon MACHADO ${ }^{3}$

${ }^{1}$ Dr. em Agronegócios. Professor Adjunto da Universidade Federal da Fronteira Sul (UFFS), Campus de Chapecó/SC. valdecir.zonin@uffs.edu.br

${ }^{2}$ Dr. em Agronegócios. Professor do Mestrado Profissional em Administração da Universidade do Oeste de Santa Catarina - UNOESC. cesar.winck@unoesc.edu.br

${ }^{3}$ Dr. em Economia Agroalimentar. Professor Associado da Universidade Federal do Rio Grande do Sul - UFRGS. dessimon@gmail.com

Recebido em: 01/02/2014 - Aprovado em: 15/06/2015 - Disponibilizado em: 15/07/2015

\section{RESUMO}

Os temas segurança alimentar e produção de biocombustíveis alimentam algumas controvérsias na contemporaneidade, seja pelos conflitos de âmbito socioambiental, seja pelas oportunidades que ambos representam. Sendo assim, este artigo busca compreender e enfatizar um conjunto de variáveis que descrevem estes conflitos e oportunidades, porém, sobretudo, responder como a produção de biodiesel, no Brasil, pode auxiliar no fortalecimento da segurança alimentar interna, relevando as posições de destaque do país no contexto internacional. As noções de oferta e demanda, seguidos por uma ótica de desenvolvimento sustentável, bem como de uma análise de redes de cooperação interorganizacionais, iluminam o debate teórico desenvolvido em torno dos temas postos. Ao final do trabalho, é possível tecer considerações que possibilitam ampliar esta discussão e ao mesmo tempo minimizar tais conflitos. Para tanto, sugere-se caminhos alternativos que fortaleçam as estratégias de aumento da produção interna de biodiesel e sua exportação, a partir da diversificação sustentável de novas matrizes produtivas agrícolas, bem como o fortalecimento dos propósitos de segurança alimentar do Brasil, no contexto internacional.

Palavras-chaves: Alimentos; Energia. Soja. Agronegócios. Sustentabilidade.

\begin{abstract}
Themes food security and biofuel production feed some controversies in the contemporary, whether by the conflicts of social and environmental context, is both the opportunities it represents. Therefore, this article seeks to understand and emphasize one set of variables that describe these conflicts and opportunities, but, especially, respond as biodiesel production in Brazil may help in strengthening the domestic food security, highlighting the positions of prominence in the country international context. The notions of supply and demand, followed by a perspective of sustainable development as well as an analysis of networks of interorganizational cooperation, illuminate the theoretical debate developed around the themes laid. At the end of the paper, it is possible some considerations that make it possible to extend this discussion and at the same time minimize such conflicts. For this, we suggest alternative ways to strengthen the strategies to increase domestic production of biodiesel and export, from the diversification of new sustainable agricultural production headquarters, as well as the strengthening of the purposes of food security in Brazil in the international context.

Key-words: Food. Energy. Soybeans. Agribusiness. Sustainability.
\end{abstract}

INTRODUÇÃO

Os sistemas de segurança alimentar têm evoluído com o passar do tempo tanto nos países desenvolvidos quanto nos

subdesenvolvidos, dado a melhorias incorporadas de ordens tecnológicas, científicas, legais e nos âmbitos sociais; muito 
embora de forma diferenciada, é claro. Entretanto, mesmo guiados por leis e regulamentações alimentares nacionais (critérios de produção, sistemas de controle alimentar, fiscalização), ainda assim, muitos desafios são postos para que se evite o desabastecimento e a insegurança alimentar.

O entendimento mais específico do real significado do termo segurança alimentar se deu a partir da I Guerra Mundial (1914-1918), que resultou devastações na produção e na disponibilidade de alimentos, no início do século passado, ganhando, desta forma, uma preocupação de segurança nacional e até mesmo internacional. A partir daí, tomou-se consciência de que os países deveriam garantir-se na formação de estoques estratégicos de alimentos para tornarem-se menos sujeitos a crises e à dependência de outros países e nações, segundo dados da Organização das Nações Unidas para a Agricultura e Alimentação, FAO (1996).

$\mathrm{Na}$ contemporaneidade, existem em torno de 850 milhões de pessoas passando fome no mundo. Este fato vem alimentando na atualidade diversas ações, envolvendo organizações presentes na sociedade e de maneira geral o Estado, no sentido de que a alimentação possa ser concebida e garantida como um direito humano fundamental (FAO, 2014).

Entretanto, em virtude da escassez de alimentos em alguns períodos, muitas vezes oriunda de problemas climáticos e de problemas relacionados a acesso aos alimentos pela população, relacionada mais expressivamente aos países em desenvolvimento e subdesenvolvidos, há um sentimento presente na sociedade de que a produção de alimentos está enfrentando a concorrência pelo uso das terras, onde, entre outros fins, inclui-se a produção de biocombustíveis. Desta forma, em alguns momentos esta produção direcionada à energia pode representar potencias conflitos com os propósitos da segurança alimentar mundial, porém, ao mesmo tempo, pode oferecer novas oportunidades nas zonas rurais.

Isto posto, o objetivo deste trabalho foi identificar variáveis que condicionam potenciais conflitos e oportunidades, entre o que é proposto como segurança alimentar e a produção de combustíveis, de forma geral, descrevendo-se em especial a situação do Brasil no que tange à produção de biocombustíveis versus segurança alimentar no contexto internacional. Desta forma, temse a seguinte questão de pesquisa: de que forma a exportação brasileira de biocombustíveis pode melhorar as perspectivas para a segurança alimentar no Brasil?

\section{METODOLOGIA}

Visando contemplar os objetivos deste trabalho, propõe-se um estudo exploratório, com análise descritiva de aspectos quali e quantitativos relacionados ao tema. A 
pesquisa será delimitada por uma análise bibliográfica do assunto, alicerçada pelo uso de ferramentas de pesquisa on line em base de dados, a leitura e sistematização de papers, além de documentos atualizados. Por outro lado, o tema segurança alimentar é analisado a partir de associações relacionadas ao termo food security (segurança alimentar), atendendo-se os preceitos de disponibilidade de alimentos e suas correlações com a produção de biocombustíveis no Brasil, com enfoque mais específico à produção de Biodiesel no país, a partir do uso da matéria prima soja.

\section{REVISÃO TEÓRICA}

\section{Relações entre oferta e demanda}

Discorrendo sobre a forma pela qual a oferta e a procura afetam o valor de troca, a visão malthusiana já tornava evidente que não é apenas à 'grandeza' da procura efetiva, (nem mesmo a grandeza da procura efetiva relativamente à grandeza da oferta efetiva), que eleva os preços, mas uma mudança na relação entre oferta e procura suficiente para tornar necessária a expressão de uma intensidade maior da procura, tanto para distribuir de modo pacífico qualquer produção efetiva, como para evitar insuficiências futuras do mesmo tipo (MALTHUS, 1996).

A partir de breve revisão malthusiana, fica entendido que um crescimento muito acelerado da população pode trazer complicações sérias aos sistemas de transportes públicos, atendimento de saúde pública, educação de massa, habitação popular, abastecimento, saneamento básico, entre outros, de forma que não apenas a segurança alimentar possa estar afetada num contexto como este, porém, podendo ser a mais importante.

Entretanto, para o real enfrentamento às questões relativas à segurança alimentar era preciso mais do que diretrizes tradicionais de expandir a produção (uma vez que Malthus já apontava para prognósticos da insuficiência de alimentos face do crescimento populacional) e aprovisionar bens para enfrentar circunstâncias adversas, como as provocadas pelo clima e os conflitos. Assim, nas primeiras décadas do século $\mathrm{XX}$, a questão alimentar ganhava novos contornos, acentuados por um contexto advindo de duas guerras mundiais e a recessão dos anos de 1930, tornando-se esta uma tarefa de estado (MALUF, 2009). No entanto, a criação de organismos internacionais, ligados de forma direta ou indireta ao tema, ocorre com maior intensidade a partir da II Guerra Mundial, período que se acentua a preocupação com a fome no mundo.

A ideia de possíveis conflitos entre a produção de biocombustíveis versus a produção de alimentos não surge recentemente, mas ainda na década de 70, quando uma importante escassez alimentar assola o mundo. Claro que, mais uma vez o problema não estava aí e, sim, num alto aumento no controle da produção de 
alimentos e no baixo acesso aos mesmos, condicionado pelo poder aquisitivo das populações menos favorecidas. Neste sentido, a essência da questão, contudo, permanece e a fome mundial constituiu-se na principal preocupação das Nações Unidas, especialmente da FAO. Então, desde os princípios de Malthus (1996), onde a insuficiência de riqueza num país fértil pode decorrer mais da falta de demanda que da falta de capital e que, em geral, apenas a fertilidade da terra não é um estímulo suficiente para o crescimento permanente da própria riqueza, existem importantes evidências de que a segurança alimentar é fonte de preocupação das nações.

\section{Noções gerais sobre segurança alimentar no contexto internacional}

Inicialmente, constata-se que no plano internacional as questões relacionadas com a produção e consumo de alimentos podem ser tratadas de forma diferenciada. As duas principais referências no que tange a países capitalistas avançados são os Estados Unidos da América e a atual União Europeia, onde a capacidade de acesso aos alimentos deixou de ser um problema central, dado ao nível de renda. Elevando-se, desta forma, a autossuficiência produtiva, baseado na agricultura intensiva e integração agroindustrial. Obviamente que este cenário não se transpõe como via de regra; já o Japão, por exemplo, embora sendo uma economia capitalista avançada constitui-se, dentre estas, no maior importador mundial de alimentos, mas com larga experiência em suportar crises alimentares.

Existem diversas agências internacionais que se preocupam e abordam este tema, como a Organização das Nações Unidas (ONU) e dentro desta o setor de Agricultura e Alimentação (FAO) criada em 1945, a Organização Mundial da Saúde (OMS), a Organização Mundial do Comércio (OMC), o Fundo das Nações Unidas para a Infância (UNICEF), entre outras. Tais organizações expressam suas ações nos conselhos, cúpulas e rodadas de negociações, onde são tomadas as decisões mais importantes (com reflexo mundial) sobre o tema, de forma geral organizadas pela FAO; aqui reza a preocupação fundamental relacionada à garantia para segurança alimentar e a estabilidade do fornecimento de alimentos no contexto mundial.

É relevante destacar que na maior parte as relações de comércio internacionais realizadas entre os países constituem-se vias de mão dupla. Ou seja, para assegurar mercados externos para exportações, países em desenvolvimento (alguns periféricos) veem-se obrigados a abrirem seus próprios mercados e sofrerem os impactos de bens importados, que em bom número de casos, recebem elevados subsídios nos seus países de origem (MALUF, 2009). Assim, estes países ficam submetidos a políticas de formação dos preços de origem (internos) às regras dos preços internacionais, afetando de 
forma diferenciada setores como a agricultura, a qual absorve impacto maior.

A partir dos diversos organismos mundiais que tratam do tema, o comércio mundial de alimentos sempre foi importante para 'alimentar' as relações econômicas entre os países, uma vez que os fluxos internacionais de produtos alimentares estão sob a determinação de instrumentos de regulação (acordos e normas comerciais), onde o caráter público não fica inteiramente assegurado. Ao contrário, é comum assistir iniciativas frustradas de liberalização comercial e de estabelecimento de regras justas de comércio, enquanto que a maior parte dos países com renda inferior, ficam submetidos à condição de importadores líquidos de alimentos. Obviamente que isto fica mais significativo quando ligado aos países com baixas estruturas produtivas, como é o caso da maioria dos países africanos.

Neste sentido, no mercado internacional de alimentos fica induzida a opção de ampliar a subordinação das dinâmicas internas aos fluxos internacionais, com fronteiras abertas e especialmente com a presença de mercados sem regulação pública. Tais mecanismos de mercado colocam o abastecimento alimentar sob o domínio das formas de regulação privada, com mínimo o quase ausente domínio público. Esta noção acaba por vezes sendo referendada pelas rodadas de negociações, como exemplo a rodada de Doha da OMC (intitulada de rodada do desenvolvimento).

\section{Segurança Alimentar no Brasil}

Como um dos precursores do que veio mais tarde se chamar segurança alimentar no Brasil, Josué da Castro, através de diversas obras, tal como Geografia da fome (1946), propõe um debate mais aberto e de caráter transformador da realidade Brasileira.

No Brasil, a instituição do Conselho Nacional de Segurança Alimentar (CONSEA), no início da década de 1990, serve como marco para impulsão de diversas políticas nacionais para minimizar a problemática da fome e resguarda-se para os possíveis desabastecimentos. A partir da I Conferência Nacional de Segurança Alimentar, em 1994, cria-se uma análise mais aprofundada sobre o problema da fome no país e a partir daí diversos governos tem desenvolvido políticas para seu enfrentamento.

A partir de 1990, além da abertura acelerada na liberalização e globalização dos mercados, o país desencadeia o início de uma série de ações que visam contrapor o temor da insegurança alimentar. Então surgem programas como Programa de Alimentação do Trabalhador (PAT), com distribuição de alimentos de estoques públicos para esta classe, nos fins da década, além de outros de forma mais recente como: Programa de Aquisição de Alimentos (PAA), Programa Restaurantes Populares (PRP), Programas de Cozinhas Comunitárias (PCC), Programa Banco de Alimentos (PBA), Programa do Leite (PL), feiras, mercados populares, 
programas de educação alimentar e nutricional, e os mais recentes ainda, tal como o Programa Nacional de Alimentação Escolar (PNAE), entre outros, conforme o Ministério do Desenvolvimento Social (MDS, 2014).

Importa destacar que o Brasil constituise num espaço privilegiado em relação ao ambiente externo, reestruturando-se aos novos padrões do consumo e colocando-se num dos líderes do comércio agroalimentar mundial, embora o acesso aos alimentos seja uma questão que preocupa grande parte da população interna. No entanto, parte deste respeito internacional é advinda da estruturação do agronegócio nacional; o setor empresarial tem celebrado a fundação da Associação Brasileira de Agribusiness (Abag), em 1995, propondo-se uma abordagem relativa à segurança alimentar como uma das maiores responsabilidades sociais dos agentes envolvidos no agronegócio, baseado numa demanda alimentar sustentada e promotora do desenvolvimento.

Elementarmente, a partir desta discussão inicial, aqui é necessário à construção de um diálogo com as questões relacionadas à produção de biocombustíveis, já que se propõe o debate difuso entre estes temas, o que se verifica na sequência.

\section{RESULTADOS}

O Programa Nacional de Produção de Biodiesel: PNPB e a dependência da soja
O Programa brasileiro de produção de biodiesel nasce a partir dos marcos regulatórios, no final de 2004, início de 2005. A ação governamental propõe, desde o início, a organização de uma cadeia produtiva que em 2009 - segundo ano de mistura obrigatória deste combustível junto ao óleo diesel mineral - ainda caminha em prol de sua consolidação, mas já garante uma mistura de 5\% desta energia renovável. Neste cenário, diversas estratégias vêm sendo implementadas pelo estado (governo federal que coordena nacionalmente o programa, por meio de ações integradas entre seus ministérios) e empresas que atuam no setor, visando esta organização do programa conhecido como Programa Nacional de Produção e Uso do Biodiesel (PNPB).

Uma importante necessidade gerada a partir do programa diz respeito à organização da matriz de fornecimento de matéria-prima agrícola para abastecer esta indústria de energia, emergente no país. Esta tem sido uma razão clara, que motiva o desenvolvimento de projetos em cada empresa de produção de biodiesel, específicos e diferenciados, levando em conta a sazonalidade e as caracterizações produtivas de cada região do Brasil, onde estão inseridas.

Neste contexto, a soja é a matéria-prima que vem sustentando, em âmbito nacional, o PNPB. Em relação à produção brasileira, a cultura da soja atingiu, na última safra colhida, 59,80 milhões de toneladas, com rendimento médio de $2.819 \mathrm{Kg}$ por hectare 
(IBGE, 2009). Porém, do total da produção de soja colhida no país, há um grande volume do produto direcionado para o mercado de exportação.

Percebe-se, assim, que um grande volume de soja é exportado, primeiramente, em forma de grãos, depois na forma de farelo e, por fim, em forma de óleo. É relevante também compreender que é dentro destes mercados (interno e externo) que as empresas buscam sua matéria-prima para a produção de biodiesel. É relevante considerar, ainda, que a cultura da soja apresentou aumento importante no rendimento em relação às exportações; o valor das exportações de soja e derivados cresceram $70 \%$ nos primeiros seis meses de 2008, quando comparados com igual período no ano anterior. $\mathrm{O}$ produto manteve a liderança na balança comercial do agronegócio brasileiro, já que $10 \%$ do total que o Brasil exporta são provenientes da soja. Assim, no primeiro semestre de 2008, o volume de exportações aumentou 4\%, atingindo 20,70 milhões de toneladas contra 19,85 em 2007. Ainda, até o final do ano de 2008, cerca de 41 milhões de toneladas de grãos, óleo e farelo de soja deverão deixar o país, CONAB (2014). Desta forma, considerando-se o ano de 2008, aproximadamente $67,70 \%$ da produção brasileira de soja foi exportada basicamente na sua maior parte na forma de grãos; esta importação impacta em alguns momentos com a demanda de uso de matéria-prima para a indústria nacional (de biodiesel ou de produção alimentar).

\section{Segurança alimentar e produção do biodiesel no Brasil}

$\mathrm{Na}$ década de 70, constata-se a escassez de alimentos em muitos países, assim a I Conferência Mundial de Segurança Alimentar, organizada pela FAO, recomenda a necessidade de melhorar a disponibilidade de alimentos no mundo, fortalecendo-se, desta forma, a noção de que deveria ser melhorada a capacidade de produção agrícola para que houvesse mais alimentos, exaltando-se, assim, o termo Segurança Alimentar.

No Brasil, especialmente após a década de 1990, vale destacar o reconhecimento da importância do agronegócio para o desenvolvimento de técnicas, ampliação de capacidade de investimento, produção e comercialização (interna e externa) de alimentos, o que fortalece e garante a participação do Brasil como líder e destaque na exportação mundial para melhorar a disponibilidade de alimentos no mundo. Além disso, deve-se verificar que a agricultura familiar no Brasil (pequenos e médios estabelecimentos) absorvem $77 \%$ da população agrícola ativa, respondendo por $38 \%$ da produção agrícola e $85 \%$ dos estabelecimentos agropecuários no país, reforçando a importância de sua participação na matriz alimentar de ordem majoritariamente interna (CONAB, 2014). Estes segmentos, portanto, complementam uma ação conjunta de aumento de oferta de 
matérias-primas (tanto para uso na alimentação, quanto na produção de biodiesel).

Assim, visando à ampliação de oferta de matérias-primas e ao mesmo tempo a diversificação para um horizonte futuro, as empresas usam como mecanismos de suprimento de matéria-prima duas principais fontes: i) mercado de óleos vegetais; e ii) mercado de grãos. Estas formas já possuem um mercado estruturado e dinâmico, tornando-se possível a busca de matéria-prima prontamente disponível no mercado local e regional. Desta forma, torna-se possível atender as demandas geradas pelas vendas de biodiesel, cujas produções finais do óleo (biodiesel) são integralmente adquiridas pela Petrobras. Estas buscas de matéria-prima ocorrem por meio da associação destas com as cooperativas de produção, agricultores, cerealistas e relacionando-se diretamente com os produtores rurais.

Desta forma, a soja é a cultura oleaginosa que lidera o ranking das culturas potenciais para a produção de biodiesel no Brasil, sendo responsável em média por $80 \%$ do óleo produzido e disponível no mercado atualmente (ABIOVE, 2014). Entretanto, por tratar-se de uma commodity, a cultura tem sua composição de preços determinado principalmente pela bolsa de Chicago/EUA, fator que determinou a oscilação de preços, somente na safra (2007/08), aumentando de $\mathrm{R} \$ 23,00$, por saca $(60 \mathrm{~kg}$ ) de grãos, para valores acima de $\mathrm{R} \$ 40,00$ na safra colhida e comercializada em 2008, estabilizando-se com preços relativamente superiores a $\mathrm{R} \$$ 30,00 no ano seguinte, CISOJA (2014).

Com relação aos cenários de produção nacional de biodiesel, é possível constatar-se que todos apontam para o aumento na produção e oferta de biocombustíveis no país, neste caso específico o biodiesel, que não foge à regra. O Brasil vem estruturando progressivamente sua matriz energética com destaque em nível mundial, já que possui ampla e escalar produção de matriz renovável, dentre eles os biocombustíveis (álcool e biodiesel com maior expressão).

Neste sentido, à medida que as projeções apontam para um aumento na oferta interna do biocombustível há uma estimativa apontando para a necessidade de aumento em relação às áreas a serem cultivadas, dentre diversas oleaginosas para a produção de biodiesel.

\section{DISCUSSÃO}

Um ponto relevante a ser considerado nesta discussão inicial diz respeito ao alto volume empregado na exportação da cultura soja (principal matéria-prima da indústria de biodiesel no Brasil), na forma de grão, farelo e óleo, que, quando somados, significa dizer que $75,69 \%$ (safra 2006), 66,69 \% (2007) e $65,51 \%$ (2008) do volume total de soja brasileira colhida nestes anos foram para atender a pauta de exportação. 
Muito embora, a soja seja uma oleaginosa que possui potencialidade agrícola já consolidada, apesar de possuir um valor percentual de quantidade de óleo relativamente baixo (18\%), se comparado com outras oleaginosas, como a canola, girassol e a mamona, o seu cultivo é muito difundido no país (BARUFFI et. al., 2007), inclusive nas propriedades familiares (em especial no sul do Brasil). Logo, é interessante constatar-se que ambos os segmentos (agricultura familiar e agronegócio) atendem simultaneamente aos mercados de energia e de alimentos de forma complementar (mercados internos e externos).

Além disso, é necessário considerar que a oscilação que esta cultura enfrenta pela regra de mercado na qual está submetida caminha no sentido contrário ao qual regrou o programa brasileiro de biodiesel, que determina a composição do preço do biodiesel através dos leilões realizados pela Agência Nacional do Petróleo (ANP). Neste mecanismo (leilão), os preços finais para a venda do biodiesel, que são produzidos pelas empresas, são fixos, independente do parâmetro matéria-prima que origina o óleo vegetal a ser usado no processo de produção de biodiesel. Deste modo, as oscilações dos preços da soja no mercado tendem a interferir em determinados momentos na competitividade do biodiesel, tornando o seu uso limitado. Este tipo de situação sugere a necessidade da busca de alternativas a esta cultura para que seja aumentada a oferta de matérias-primas agrícolas, com preços mais estáveis do ponto de vista econômico, reduzindo, desta forma, possíveis incertezas e potencializando novos arranjos produtivos nos sistemas de produção do biodiesel.

Com relação ao volume total de biodiesel produzido na atualidade e projetada para os próximos anos, considera-se significativo, pois o mesmo desloca uma fração importante do óleo vegetal para a esta produção, transferindo-o de suas rotas originais (geralmente exportação). Esta discussão e análise são elementares, pois a partir delas pode-se verificar a necessidade real de matéria-prima na forma de óleo ou grãos, que são indispensáveis para a constituição da cadeia de suprimentos tanto na indústria energética quanto alimentar (com base na soja).

No entanto, a produção de matériasprimas agrícolas para a produção de biocombustíveis impõe na contemporaneidade a um novo paradigma de produção agrícola e industrial, sendo uma necessidade a integração das culturas de agroenergia e agroalimentar (RAGAUSKAS; WILLIAMS; DAVISON et. al., 2006). E, à produção de biocombustíveis, não constituem qualquer ameaça, do ponto de vista da segurança alimentar, dado que os biocombustíveis podem ser percebidos como matéria-prima para a produção de alimentos, necessários ao sustento do planeta (REINBERGR, 2008).

Por outro lado, para Flammini (2008), houve um importante aumento concomitante 
nos preços dos óleos vegetais, commodities alimentares e commodities em geral, os quais ocorrem pela progressão mundial na produção dos biocombustíveis, mas ao mesmo tempo pela forte elevação nos preços dos fertilizantes e especialmente no Brasil do petróleo, que experimentou novas crises de preços, após 1973 e 1979, onde ocorreram as duas grandes crises mundiais de petróleo, afetando obviamente as commodities e os preços dos alimentos.

Por outro lado, a produção de biocombustíveis pode oferecer oportunidades de geração de renda nas zonas rurais, podendo ajudar a melhorar perspectivas para a segurança alimentar, ou seja, pode oferecer uma oportunidade para os agricultores tradicionalmente espremidos pela baixa dos preços agrícolas - para obter melhores condições de comércio. E, para países com abundantes áreas de terras, o acesso aos mercados de bioenergia e aos alimentos, ao mesmo tempo, pode auxiliar os países mais pobres e comunidades a avançar para a segurança energética, mitigar os impactos negativos dos elevados preços do petróleo e, assim, promover a segurança alimentar, além da diversificação das culturas homogêneas (WANG et. al., 2009).

No que tange, especialmente, à segurança alimentar importa ainda constatar que no Brasil a maior parte dos programas destinados a subsidiar alimentação para a população necessitada é coordenada pelo Ministério do Desenvolvimento Social e
Combate a Fome, que divide atribuição com outros ministérios e sob a tutoria da presidência da república. Como exemplo já citado, o PAA foi responsável pela compra da produção agrícola de 113 mil produtores, beneficiando 10 milhões de pessoas e um investimento de $\mathrm{R} \$ 445$ milhões.

As aquisições do governo federal, através dos programas de aquisição de alimentos, reforçam em especial o papel e importância da agricultura familiar neste processo, fortalecendo-se a consolidação das políticas nacionais de segurança alimentar interna.

Muito embora, a dinâmica mundial do comércio de alimentos (de forma geral) tem adotado as práticas ditadas pelas próprias regras de mercado, é relevante apontar que ela se constitui por muitas vezes em arenas de conflitos de interesses de vários tipos, opondo consumidores e empresas, empresas concorrentes, entes públicos e agentes privados.

\section{CONCLUSÕES}

Como conclusões deste trabalho é possível afirmar que nesta arena de conflitos criados em torno destes temas, os mesmos possuem uma pequena relevância em nível de Brasil, dado as condições produtivas do país e sua liderança mundial na exportação de alimentos. Isto não faz com que se descarte a existência desta critica, mas é possível inferir que o país não a coloca numa pauta de 
primeira ordem. Muito embora, pode-se reconhecer que no plano mundial a leitura seja diferente, mudando de região para região.

Outro ponto importante a concluir é que o provável aumento do uso de biodiesel no óleo diesel mineral no Brasil provocará uma maior disponibilidade tanto de soja na forma de grão quanto na forma de farelo, para uso interno, o que aumentará a disponibilidade de proteína presente dentro dos $80 \%$ do peso bruto deste grão; ao passo que, da mesma forma, aumentando-se as exportações líquidas do biodiesel produzido internamente, se aumentará o valor agregado interno dos produtos oriundos da soja, provocando-se uma maior retenção de farelo e óleo vegetal no país, favorecendo, deste modo, uma melhor condição para a segurança alimentar interna.

No entanto, a preocupação existente entre esta dinâmica representar conflitos ou oportunidades pode ser melhor resolvida à medida que o país fortalecer a diversificação da produção, visando o atendimento destes mercados (alimentos e energia), interdependentes e complementares, ao mesmo tempo. Atualmente, há mais razões para se acreditar nas oportunidades do que nos potenciais conflitos entre estes fins.

\section{REFERÊNCIAS}

ASSOCIAÇÃO BRASILEIRA DAS INDÚSTRIAS DE ÓLEOS VEGETAIS (ABIOVE). Dados do complexo soja, 2014.
Disponível em: 〈http://www.abiove.com.br> Acesso em: 26 dez. 2014.

BARUFFI, C.; PAVAN, M. O.; ZANOTTI JUNIOR, M.; SOARES, M. Y.; CORTEZ, C. L.; BRAZ, C. P.; FUNCHAL, P. H. Z.; LASCALA, T. L. S.; BERMANN, C. (Org.). As novas energias no Brasil: dilemas da inclusão social e programas de governo. Rio de Janeiro: FASE, 2007.

CASTRO, J. Geografia da fome. Rio de Janeiro: O Cruzeiro, 1946.

COMPANHIA NACIONAL DE ABASTECIMENTO (CONAB). Agricultura e abastecimento alimentar: políticas públicas e mercado agrícola. Brasília: CONAB, 2014.

CENTRO DE INTELIGÊNCIA DA SOJA (CISOJA). Dados e estatísticas. Disponível em: <http://www.cisoja.com.br > Acesso em: 28 mai. 2014.

INSTITUTO BRASILEIRO DE GEOGRAFIA E ESTATÍSTICA (IBGE). Levantamento sistemático da produção agrícola (LSPA). Fascículo indicadores IBGE. Disponível em: <ftp://ftp.ibge.gov.br/Producao_Agricola/> Acesso em: 27 mai. fev. 2014.

MALTHUS, T. R. Princípios de economia política e considerações sobre sua aplicação prática: ensaio sobre a população. Trad. Regis de Castro Andrade et. al. São Paulo: Editora Nova Cultural, 1996.

\section{MALUF, R. S. Segurança alimentar e} nutricional. 2. ed. Rio de Janeiro: Vozes, 2009.

MINISTÉRIO DO DESENVOLVIMENTO SOCIAL (MDS). Disponível em:

<http://www.rts.org.br> Acesso em: 28 mai. 2014.

ORGANIZAÇÃO DAS NAÇÕES UNIDAS PARA A AGRICULTURA E ALIMENTAÇÃO (FAO, 1996; 2008).

Disponível em <http://www.fao.org/> Acesso em: 25 mai. 2014.

RAGAUSKAS, A. J.; WILLIAMS, C. K.; DAVISON, B. H. The path forward for biofuels and biomaterials. In: Science. v. 311, jan. 2006. 
REINBERGR, O. Long-term outlook of bioetanol production in the Czech Republic.

In: Listy Cukrovarnicke a Reparske. v. 124, 2008.

WANG, H.; WAN, L.; ZEHNDER, A. J. B.

Water scarcity and food trade in the Southern and Eastern Mediterranean countries. In:

Food Policy. v. 1. 32, 2009. 